\title{
A Review on NBC Body Protective Clothing
}

\author{
M. Boopathi*, Beer Singh and R. Vijayaraghavan \\ Defence Research and Development Establishment, Gwalior-474 002, India
}

\begin{abstract}
Body protective clothing and suits against NBC agents are playing vital role in the NBC defence during war and training scenarios. Hence, reviewing about the past, present and expected future development in this NBC protective clothing area is an important task. This review brings out a sequence related to the NBC protective clothing, their type, various materials available for the development of NBC clothing, their evaluation procedures, washing methodologies, decontamination methods. Moreover, the futuristic trends in NBC protective clothing such as detection and decontamination integrated NBC protective clothing based on electrospun nanofiber technology and molecularly imprinted polymer technology are also reviewed and discussed.
\end{abstract}

\section{GENERAL INTRODUCTION}

The protective clothing used in the World War I against chemical warfare agents (CWA) consisted of rubber clothing, which, together with gloves and boots, to cover the entire body apart from that protected by the mask. Clothing of this kind is usually characterized as impermeable. This means that $\mathrm{CW}$ agents cannot pass through the material and also the fact that perspiration released from the skin is also prevented from passing out. Consequently, to wear clothing of this kind for longer periods is extremely uncomfortable and in hot climates the period during which protective clothing of this kind can be worn will be very short.

In order to reduce the heat load developed due to wearing of impermeable protective clothing, permeable clothing was designed and developed, where a layer of finely distributed active carbon, either bound in polyurethane foam or as particles of carbon, is bound between two layers of textile. A layer of this kind consisting of active carbon which permits water vapour released from the body to pass through. The active carbon absorbs CWA and thereby prevents them from passing through to the skin. This layer of carbon is never used alone but is combined with different textiles.

A present CWA protective suit is an example of clothing made of permeable material. The largest difference is that inside the impregnated outer material there is a layer of active carbon on a suitable carrier. The CWA protective suit can be used instead of a battle dress or as an overall placed over the uniform. An alternative is to use inner clothing with a layer of carbon which is worn underneath the normal uniform.

Impermeable suits can be used in severely contaminated environments, e.g., during decontamination. The heat load can be reduced by ventilating the clothing with fans. However, this solution is too vulnerable to be used.

*Address correspondence to this author at the Defence Research and Development Establishment, Gwalior-474 002, India; Tel: +917512341848, Ext. 162; Fax: +917512341148;

E-mail: mannanboopathi@yahoo.com,mbpathik@yahoo.co.uk
In order to achieve short-term CWA protection, it is possible to use overalls made of different plastic material. Many research and development occurred around the globe to achieve the body protection equipment time to time and are discussed sequentially thought this article.

\section{IMPERMEABLE SUIT}

Impermeable NBC-protective suit [1] was developed for the German civil defence personnel of 245 NBC platoons with 42 helpers in each unit. The main tasks for the civil defence personnel were (i) detection of chemical contaminations (ii) sampling (iii) marking and monitoring of contaminated areas (iv) decontamination of people and equipment and (v) decontamination of important contaminated roads. In order to perform above tasks, the civil defence personnel should be first themselves protected from the chemical hazards, hence, a NBC protective Zodiak was designed and developed to provide protection from chemical warfare agents including industrial toxic chemicals. The developed Zodiak was a two piece suit and two persons are required to help the person who is wearing that. Several modifications are carried out in the suit to use it by the wearer with out the help of others in case of an emergency. The essential requirements for the chemical protection laid down by the Germans were (i) the cloth should provide protection against Sulphur Mustard (HD) and Sarin (GB) for five hours (ii) the cloth should provide 30 minutes protection against toluene, 1,2-dichloroethane, triethylamine, n-octane, methanol, hydrogen chloride, nitric acid $(65 \%)$, sulphuric acid (98\%), chlorine gas and ammonia gas.

\section{PERMEABLE SUITS}

A new approach [2] to heat stress relief in chemical protective clothing was put forwarded by the Israelis. The requirement of efficient protective clothing is widely accepted in view of the threat posed by the various vesicants and other chemical warfare agents which penetrate through the skin. Impermeable protective clothing was thought to provide good protection against the chemical warfare agents; however, being impermeable and also due to perspiration, they create an untolerable barrier against the normal cooling processes of the human body. Hence, one of the main requirements from a functional protective suit is to allow adequate cooling of the 
body, which is a vital necessity. So as to over come the problem associated with heat stress, the well known breathing protective materials have been developed. These materials are air permeable due to an open porous structure and it helps in the removal of perspiration from the protective suit. The porous materials are made up of activated charcoal and the chemical warfare agents are absorbed on the charcoal. Many disadvantages are associated with the protective clothing made from breathing materials including penetration of aerosols, contamination by fuels, oils, solvents, poisons and the protective power of the cloth degrades within a few days of use without any external contamination. Hence, alternative material was developed [2] by a different approach in order to provide heat stress relief in protective clothing based on the selective water permeability of impermeable clothing and it have the capability to act as a barrier for CWA. Certain hydrophilic plastic materials are having the ability to allow water transport through them and the following are some in the category such as poly vinyl alcohols, some varieties of polyurethanes, cellophane and others. However, these water permeable polymers are not good barriers against CWA, if they are wet (Nylon and tedlar are resistant to HD and loose their activity as soon as they are hydrophilized). This problem was avoided by using activated charcoal in the structure of films made of water permeable plastic material with pore free structure. The protective clothing made by this new approach exhibited good chemical protection and heat stress relief properties. Penetration of agent through this material is based on diffusion. In case of a CWA exposure, the small quantities of CWA which may penetrate through the plastic material are stopped by the activated carbon which is a part of protective layer. Due to this two stage mechanism of chemical protection, both the thickness and the activated carbon content of the protective layer can be significantly lowered relatively to the breathing materials for attaining equivalent levels of protection. The reduced thickness and weight of the protective material directly helps to have less discomfort upon wearing the protective garments with enhanced thermal relief properties. The excellent thermal stress relief exhibited by this material was due to the presence of pore free structure, which enhances the thermal conductivity and also high water permeability of the material. The developers also performed many physiological tests on the water permeable material and found to stabilize the body temperature after two hours of work and it reveals that a state of equilibrium was established between the heat accumulated and the heat dissipated. However, in the breathing protective garments a continuous raise in the body temperature was observed. In addition, water permeable impermeable garments are aerosol proof and their chemical resistance is not affected by wind velocity and/or drop impact velocities. Moreover, due to the pore free impermeable structure, these materials can be easily decontaminated using liquid decontaminants during wearing or afterwards. A carbon containing protective fabric [3] with a fine carbon was made by the Chinese researchers for their forces. The material is consisting of good permeable gauze, fine carbon and mixed binder. The gauze is the carrying layer onto which the fine carbon $\left(900 \mathrm{~m}^{2} / \mathrm{g}\right)$ was fixed with the binder and the resultant material's surface area was $860 \mathrm{~m}^{2} / \mathrm{g}$. The static and dynamic adsorption characteristics of the material were evaluated. The experimental data revealed the applicability of the new carbon containing protective clothing material in canister mask, collective protection equipment and the adsorption inner layer of protective clothing.

In addition to the above, another carbon containing flannel [4] was used as the inner layer in the development of Chinese M-82 permeable chemical protective suit. The suit was made up of cotton flannel; one side of the cotton flannel was finished with active carbon and polyacrylate binder and other side of the cotton flannel was finished with oil repellent agent. After extensive physico-mechnical studies, the suit was mass produced and supplied to the Chinese army. The static adsorption studies are carried out against benzene, HD gas and Soman (GD) etc., by adopting high vacuum McBain quartz spring method and head space gas chromatography method. Moreover, charcoal containing permeable chemical protective suit was developed rapidly as chemical protection equipment and was largely provided to the army personnel in many countries since 1960s. Chinese also developed such a suit based on the principles of wicking and spreading oil repellent adsorption [5]. The developed suit exhibited good ability to resist pressure permeation of chemical warfare agents' droplets and decrease the loading capacity of liquid chemical warfare agent per unit area of fabric. This suit consisted of two layers in which outer layer was made up of vinylon-cotton blend fiber and was finished for camouflage and water proofing and the inner layer was made of cotton flannel. One surface of the inner layer was finished with active charcoal powder-adhesive mixture and the other was finished oil repellent layer. The suit was tested for many parameters including liquid holding capacity, gas and liquid penetration, charcoal binding strength, air tightness etc. The suit had protection factor of more than 90 with $1.3 \mathrm{~kg}$ weight and three years storage life.

\section{ACTIVE CARBON BASED PROTECTIVE CLOTHING}

Saratoga carbon pellet technology [6] in chemical warfare protective fabrics was developed by Blucher $\mathrm{GmbH}$, Germany. Saratoga protective textiles have gained much attention among the forces of USA and NATO. Saratoga was originally developed by Blucher GmbH of West Germany in which they used spherical activated carbon adsorbers that provides excellent chemical agent protection, comfort, launderability and reusability. The properties continue to be improved by further refining the present technology. Chemical defence started in the earlier days by using the universal adsorber activated carbon and now also it is used in all the permeable chemical protective clothing made for defence personnel. The adsorption characteristics of the activated carbon is not selective, however, it provides an advantage in personal protection based on its adsorbing ability of full range of potentially hazardous chemical vapours. The surface area of the available active carbon should be in between $500 \mathrm{~m}^{2} / \mathrm{g}$ and $1500 \mathrm{~m}^{2} / \mathrm{g}$ so as to provide good protection against CW agents. Granular and powdered activated carbons are less expensive while fibrous and fabric forms are very expensive. Saratoga spherical adsorbers are of intermediate expense with good performance benefits than granular activated carbon. Activated carbon is nothing but a carbon with a mixture of polar and 
non-polar surface sites. Ammonia treatment of activated carbon leads to the conversion of $-\mathrm{OH},=\mathrm{O}$ and $-\mathrm{O}$ - groups to nitrogen containing groups and these groups are less sensitive to water. Water vapors are readily adsorbed by the adsorber and are displaced by toxic chemicals due to their greater adsorption ability. In conclusion, this study recommended a chemical protective suit with a range for spherical adsorber distribution from $50 \mathrm{~g} / \mathrm{m}^{2}$ to $200 \mathrm{~g} / \mathrm{m}^{2}$ and this versatility enable adaptation to the specific military needs of the user.

Again, new and improved CWU/66P Chemical protective clothing system [7] was developed for the US air crew application. The United States Air Force started the development of a fabric system for their crews in 1981 in order to overcome the threat of chemical warfare agents' exposure. Earlier they have used British Mark I under coverall, which is a non-launderable with relatively low air permeability and must be worn along with flight suit and non-thermal long under wear. Moreover, the other limitations associated with that British Mark I suit are the increased thermal burden, low flame resistance and high cost of a disposal garment and requires extra time to don and doff. The new chemical protective clothing combines the three pieces of equipment into a single layer system providing improved comfort. Three material technologies were considered during the development and all of the material technologies were permeable woven fabric systems (laminated fabric approach, intimate blend fabric approach and resin loaded fiber approach). Among the three approaches, laminated fabric approach and intimate blend fabric approach were evaluated during the design, test and evaluation trials. In June 1988, the laminated fabric system offered the best opportunity to support operational forces needs. The resultant CWU/66P chemical defence protective coverall manufactured from PBISARATOGA protective textile exhibited good chemical agent protection capability before and after repeated washings, reduces thermal burden on the individual air crewmen, is reusable, and provides durability for long term use.

\section{POLYBENZIMIDAZOLE (PBI) SARATOGA PROTECTIVE TEXTILE}

Saratoga protective textile used in the production of chemical defence clothing is very popular protective material among NATO armed forces and it was originally developed by Blucher $\mathrm{GmbH}$ of Germany in close association with USA, European and Israeli governments and Industries. The Saratoga system is a family of different materials using spherical activated carbon adsorbers that have demonstrated excellent chemical agent protection, comfort, launderability and reusability. PBI Saratoga Protective textile is made by first bonding small spherical adsorbers in the range between 0.2 and $0.4 \mathrm{~mm}$ diameter to the outer shell fabric. The outer shell fabric is made from a blend of PBI (20\%) and Nomex (80\%) and weighs approximately $150 \mathrm{~g} / \mathrm{m}^{2}$. The spherical adsorbers distribution was 25 mesh and density was $120 \mathrm{~g} / \mathrm{m}^{2}$. A light weight liner fabric (PBI 20\% and Nomex 80\%) was laminated to the spherical adsorbers having shell fabric in order to get additional protection and comfort to the suit. The resultant monopack PBI SARATOGA weighed approximately 460 $\mathrm{g} / \mathrm{m}^{2}$. The critical aspect of this technology is dependent on the choice of adhesives used in the laminating and manufacturing process. The glue must be strong enough to withstand laundering and wear and at the same time should not cover the spherical adsorbers reducing its surface area and thus preventing the adsorption of agents. Moreover, the new personal chemical protective suit [8] of the U.S. military services (JSLIST suit) was developed by BLUCHER GmbH using fifty eight different suit configurations by combining various technologies. The suits are subjected to a comprehensive range of field tests along with physical, chemical and physiological laboratory tests for five years. The suits are field tested over forty five days at nine locations including three different environmental conditions, the suits are also subjected to six field launderings. The Saratoga chemical protective overgarment of the U.S. Marine Corps was established as benchmark. Based on the filed trials the following are kept as requirement for a chemical protective suit (i) wear time in the non chemical environment for more than 45 days (ii) protection time for more than 24 hours (iii) 6 times of field launderability (iv) overgarment, aviator and duty uniform as suit configurations and (v) size of suit in seven sizes ranging from small to large.

\section{CARBONACEOUS RESIN SORBENTS FOR CHEMICAL PROTECTION}

Carbonaceous resins sorbents [9] for chemical protection was developed by the Americans. Carbonaceous adsorbents are the patented synthetic adsorbents and these are prepared from macrorecticular copolymers. The resultant adsorbents are carbonaceous replicas of the synthetically designed macroreticular copolymer from which they are prepared. These adsorbents have chemical structures that are in between that of the porous polymer precursor and granular activated carbon. They are hard, non-dusting spherical adsorbers with a tailorable surface, pore size distribution and surface area. As a result, these adsorbers can be made with a wide range of properties so that they can be optimized for any given applications. Carbonaceous adsorbents can be tailored by changing the characteristics of the starting copolymer, changing the pyrolysis conditions or changing the activation conditions.

\section{USE OF UNDER GARMENT FOR PERSONAL NBC PROTECTION}

The concept of using and under garment [10] for personal NBC protection was introduced by a well known German company Blucher $\mathrm{GmbH}$ working in this area. NBC protective over garment was introduced in 1960. The gulf war revealed the disadvantages of over garment usage by imposing high physiological load on the wearer. Subsequently, integration of NBC protection in the clothing system of the soldier was considered. To integrate, a protective undergarment was brought out after long experimentation and it exhibited versatility and optimal protective characteristics which are essential for attaining good protection. In addition to the chemical protection, the undergarment provided excellent wear comfort and washability. These composite textiles are named as pyjama. The chemical protection provided by the pyjama varied depending on the quantity of spherical carbon adsorber 
used. Coverage of $80-120 \mathrm{~g} / \mathrm{m}^{2}$ of spherical adsorbers in a distribution between 11 and 25 mesh was utilized if possible. The undergarment pyjama can be combined without any problems or limitations with (i) air permeable textile outer wear (ii) semi permeable outer wear or (iii) air tight impermeable protective clothing. Chemical protection as well as wear physiology of the pyjama under garment have been tested and documented by several agencies such as TNO-Netherlands, Porton Down and Royal Military College of Science-UK, Germany and US laboratories of the forces. NATO air forces and Swedish rescue board made a decision use this concept and technology for their crews.

Another new generation of permeable NBC protection clothing [11] for hot climate condition based on the experiences of gulf war was developed by Alfred Karcher $\mathrm{GmbH}$ Company to over come the problems. The protective clothing Karcher Safeguard ${ }^{\mathrm{TM}}$ 3002-A1 was consisting of a multilayered textile fabric with an integrated layer of active carbon. The outer layer which was manufactured of permanently flame retardant fibre guarantees effective protection to the wearer against thermal radiations as well as the penetration of radioactive particles or pathogens through the textile compound onto the skin. The oil and water repellent outer layer prevents adsorption of all liquid chemical warfare agents. The inner layer behaves as a textile filter and the wear against chemical weapons and aerosol and gas form are achieved by the integration of a specially developed activated carbon component to the filter layer. The large effective surface area of the active carbon layer traps the chemical warfare agent molecules and thus prevents any damage to the body. This suit also exhibited good physiological wear and protection qualities that are able to overcome the problems associated with the permeable protective clothings between 1970s and 1980s.

Czechoslovak textile adsorbents and possibilities of their utilization for noxious compounds trapping were introduced to the world [12]. The non-woven adsorption textile developed was consisting of powdered activated carbon as an efficient component fixed with an acrylate binding agent on a textile carrier made from the random polyester fibers which efficiently trapped the toxic vapours and gases. These adsorbents had some excellent characteristics when compared to other types of area adsorbents and these properties are utilized for making chemical protection against chemical warfare agents and industrial harmful compounds with a precutaneous effect. In addition to good protective nature, this material displayed a reduced flammability, good mechanical resistance and very high permeability.

VISAC-activated carbon fibers in composites for chemically protective clothing were developed at Tempe University of Technology, Finland [13]. Very high functional protective suits were manufactured from selected woven, knitted and activated carbon fiber fabrics. The activated carbon fabric was exhibiting an ultra high specific surface area and high adsorption capacity for organic substances. The general idea of this work was to make various NBC protective cloths which fulfill technical requirements needed for clothing comfort. The starting fabrics were combined to various laminates, which were subjected to chemical warfare, fire retardant, thermal resistance and textile mechanical testing. The laminates were sewed onto NBC suits carefully by applying a tight, adsorbing seeming system. The developers gave special attention to attain good breath-ability and clothing physiological properties to overcome the thermal stress faced by the user. The final results of these experimentations with the NBC protective suits made from VISAC-AFF laminated fabrics revealed a high chemical protection level, excellent clothing comfort and good mechanical properties.

\section{NBC PROTECTIVE FILMS}

Some new generation NBC films are produced by cross lamination by the Switzerland scientists [14]. The films are very strong and light weight with good resistance against chemical warfare agents. The principle behind in the cross laminated film manufacturing is nothing but plywood effect and barrier layer concept. The developed material is based on cross lamination of anisotropic webs, the resultant material exhibited huge mechanical strength and its barrier properties are mainly provided by the central layer. The NBC film was made by a three step process by combining of three layer positive bias, barrier layer and three layer negative bias, respectively. The developed film exhibited capability to withstand HD for more than $72 \mathrm{hrs}$. Based on these NBC films, (i) personnel protective equipment are developed including over shoes, decontamination kit pouches, wraps, decontamination aprons, foxhole covers, jackets and trousers and (ii) protection for material are made such as tent, bags for tents and other items, protective covers for vehicles, aircraft etc.

\section{SCREENING AND EVALUATIONS OF PROTEC- TIVE SUITS}

A screening test for selecting chemical protective clothing [15] was brought by the American scientists from Loas Alamos Natioanl Laboratoty (USA). It is well known that the clothing protects the wearer from hazardous chemicals by interposing a barrier between the challenge and the individual. This carrier can fail by the chemical passing through either openings, closures, seams, valves, pinholes or tears, or through the material itself. The first process which is based on the penetration is a property primarily of the mechanical design fabrication and physical properties of the garment material. The second process is permeation and which is primarily a function of the chemical properties of the challenge chemical and the garment material. The basis of the screening methods mostly used is based on the solubility of the challenge chemical in a material. This rule has some basis in simple permeation and diffusion theories. The parameters that are taken in to account during regression with solubility parameter differences testing are breakthrough time, permeation rate, differences in solubility parameters, initial thickness and log of variables. In case of regression with measured solubilities, the parameters taken into account are breakthrough time, permeation rate, volume change, moles adsorbed, initial thickness, final thickness, weight change and log of variables. Discrimination analysis also preformed for the screening of garments, in this case probability of a predicted value being either greater or less than the pre-selected discriminant value is 
estimated and taken in to evaluations. The parameters studied here are breakthrough time and permeation rate.

Research on the deterioration of human performance [16] with use of chemical protective clothing was carried out by the South Africans. Deterioration of human performance when wearing chemical protective clothing is a well known problem and the most important reasons for this are (a) physiological strain due to heat stress (b) physiological factors due to general discomfort as well as specific effects from the protective ensemble and (c) ergonomic or functional limitations due to the bulky equipment. When evaluating the foregoing factors, different variable need to be considered including clothing characteristics, the environment, the man and his physiological/psychological makeup and the task. This kind of study is very essential to carry out in the tropical regions due to the hot climate prevailing in those areas.

New protective material test system for the evaluation of multiple challenge chemicals [17] was introduced by Singaporeans. Testing of protective materials are performed usually with only one pure challenge chemical and this situation good for the laboratory evaluation, however, in the battle filed the toxic chemicals may be a mixture of several compounds or mixed with solvents and the effects of these mixtures on the penetration characteristics of protective materials are unknown. In some events it was realized that a pure toxic agent was not penetrated through a material, whereas, a mixture of that compound with an organic solvent penetrated the protective cloth due to the attack of the solvent and the solvent degrades some polymers making it less resistant to the toxic compound. In order to study this, Singaporean DSO national laboratories developed a special test cell and utilized for further evaluations.

Automated test systems [18] for NBC protective materials were developed by TNO Prins Maurits Laboratorium to perform the vapour and liquid convective flow test for air permeable protective clothing materials. After challenging the material the amount of penetrating agent was collected in a gas stream and analyzed on line using gas chromatograph with a flame ionization detector. In this way the breakthrough concentration of the agent penetrating the sample was measured continuously. The system was able to test 12 material samples simultaneously for their quality control during production and can be utilized for the agents HD gas, GD and VX. Moreover, protection afforded by NCBF suits for its wear and tear [19] was revealed by the Netherlands scientists working in their national defence research organization TNO. In order to reduce the amount of labour involved in conducting large scale troop trials for studying the degradation in the protection exhibited by NBCF suits, they have adopted an alternative test based on a bicycle ergonometer and also introduced to the world community. In comparison with a troop trial using four different suits the validity of the bicycle test is undertaken. The study revealed the following conclusions (i) the bicycle ergonometer test is a rather good method to simulate sweat poisoning and wear and tear, (ii) the Saratoga based suits give good to excellent chemical protection, (iii) in general wear and tear only had a minor effect on the protection and the cycling test indicates probably weak spots in carbonized suits (iv) the nuclear heat flash protection as well as fire retardancy of the suit is satisfactory.

\section{DECONTAMINATION OF PROTECTIVE SUITS}

A decontamination procedure [20] for the over garments was developed by the German federal armed forces defence science agency. According to their current long term planning and regulations, contaminated over garments will be replaced by new clothing and the contaminated clothing will be packed and stored in NBC transport bags. This is also valid for the permeable chemical suit which was originally designed for disposable after a use. Some of the procedures used to decontaminate impermeable rubber suits are (i) decontamination with aqueous solution of $\mathrm{Ca}(\mathrm{OCl})_{2}$ (ii) with aqueous solution of $\mathrm{Ca}(\mathrm{OCl})_{2}$-emulsion and with steam in gas tight insulated chamber. Organic solvents such as perchloroethylene are effective for the decontamination; however, the solvent blocks the active surface area of the charcoal layer and destroys the flame resistance of the outer garment. Hence, thermal procedures are only recommended such as decontamination with steam/hot air and decontamination with exhaust gases from a combustion engine. Germany had a long history in using insulated chambers for decontamination purposes. During World War II insulated chambers were in the use for the decontamination of heavy rubber suits. Two chambers are used for the decontamination one for steam mode and another for drying mode. The agents used for decontamination studies are HD, VX and a simulant of VX. The decontamination main mechanism is based on hydrolysis; the temperature maintained was $170{ }^{\circ} \mathrm{C}$ for 30 minutes. Decontamination using exhaust gases from combustion engines started in 1970s with tents. This standard procedure was introduced in the army as an interim solution. VX $10 \mathrm{~g} / \mathrm{m}^{2}$ was decontaminated on the garment by treating the garment at $170{ }^{\circ} \mathrm{C}$ for $60 \mathrm{~min}$, after the treatment the amount of $\mathrm{VX}$ found was $0.001 \mathrm{~g} / \mathrm{m}^{2}$ in the charcoal layer and no VX was detected in the outer garment.

\section{LAUNDERING OF PROTECTIVE SUITS}

Effect of laundering [21] on anti chemical protective clothing was carried out by the Netherlands scientists working in their national defence research organization TNO. Most air permeable NBC protective clothing was developed as disposable systems, to dispose of after contamination or after certain time of use. Due to the increase of costs and for training purposes reusable suits are more desirable. In 1990s many companies reported the development of reusable chemical protective clothing based on laundering. In the case of laundering, outer shells containing cotton are generally improved if an oil repellent layer was used during the finishing. Non-woven type of active carbon layers degrade mostly during laundering and a better foam system can with stand up to five launderings. Carbon spheres on textiles of Saratoga based suits are mainly degraded by soap residues blocking the adsorption capacity of the spheres. These effects are relatively minor and can with stand up to 20 launderings. The launderings are performed with 18 types of NBC protective garments in this study such as foam type, Saratoga and Non-woven. Three different types of detergents are used with standard US or European laundering machines at 40 or 60 
${ }^{\circ} \mathrm{C}$. The degrading effects observed with suits are dependent on the type of detergent used.

\section{PERMEABLE PROTECTIVE CLOTHING DEVELOPED BY THE INDIAN DEFENCE RE- SEARCH AND DEVELOPMENT ORGANIZATION (DRDO)}

Indian DRDO under took many developments to protect their defence service personnel from NBC hazards. In this kind many versions of chemical protective suits are developed both permeable and impermeable. The recently developed Mark-IV permeable suit with active carbon sphere technology is depicted here along with other protective tools (Fig. (1)).

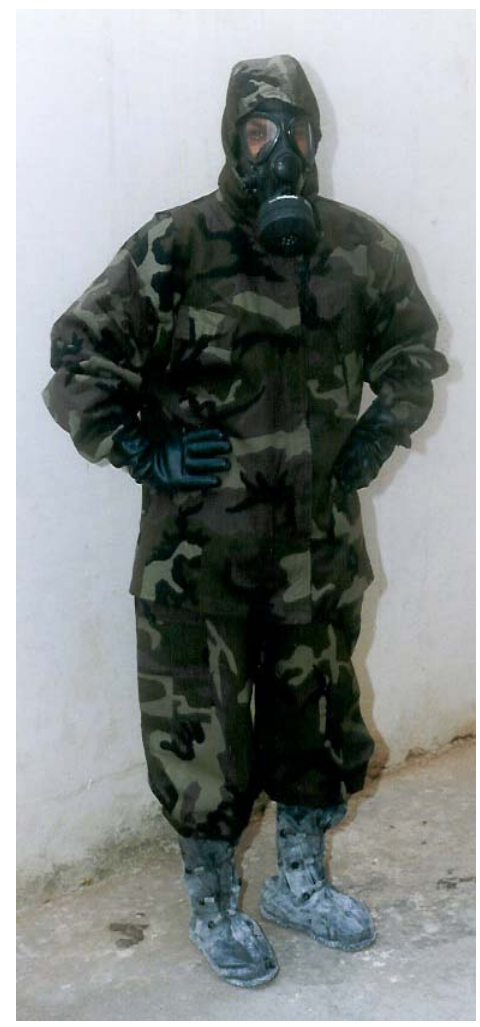

Fig. (1).

\section{FUTURE TRENDS IN THE PROTECTIVE CLOTHING}

\subsection{Light Weight Non-Woven Fabrics and Elec- trospun Nano-Fibers}

Development of lightweight non-woven protective clothing for chemical and biological warfare protection was reported by Texas Technical University [22]. Nonwoven substrates are novel and having promising approach for use in the development of protective clothing materials based on their lightweight, breathablity, and comfortability. The purpose of their work was to use state-of-theart non-woven technology to produce fabrics capable of providing chemical protection and they have produced non-woven substrates with high tensile strength and also incorporated an activated carbon layer so as to get significant amount of chemical adsorbency. Electrospun nanofibers [23] are introduced by the National University of Singapore researchers in order to solve the global issues related to chemical and biological warfare agent protective clothing. Nanofibers are able to form a highly porous mesh and their large surface-to-volume ratio improves performance for many applications. Electrospinning has the unique ability to produce nanofibers of different materials in various fibrous assemblies. The high production rate and simplicity of the electrospinning setup makes its utility in academia and industry. Various nanofibers can be made for applications in energy storage, healthcare, biotechnology, environmental engineering, and defence and security. Nanostructures with their small size, large surface area, and light weight will improve, by orders of magnitude, to detect chemical and biological warfare agents with sensitivity and selectivity, to protect through filtration and destructive decomposition of harmful toxins and also to provide site-specific in vivo prophylaxis. Nanofibers based on polymers are considered to be excellent membrane materials for the above mentioned purposes because of their light weight, high surface area, and breathable (porous) nature. The high sensitivity of nanofibers towards chemical or biological warfare agents makes them excellent candidates as sensing interfaces. Various methods of modifying nanofiber surfaces to enhance their capture and decontamination capability of warfare agents are currently under investigation [23] based on chemical surface modification and attachment of reactive groups such as oximes, cyclodextrins, and chloramines and those bind and detoxify warfare agents. Preliminary tests conducted in this study using chemical warfare simulants such as paraoxon and dimethyl methyl phosphonate on the functionalized fibers show evidence of decontamination. Metal nanoparticles (Ag, $\mathrm{MgO}, \mathrm{Ni}, \mathrm{Ti}$, etc.), which have proven abilities in decomposing warfare agents, can also be embedded in the nanofibers. Functionalized polymer nanofibre membranes [24] for protection from chemical warfare simulants are developed and evaluated based on their hydrolysis study. A catalyst for the detoxification of nerve agents was synthesized from $\beta$ cyclodextrin ( $\beta$-CD) and o-iodosobenzoic acid (IBA) and functionalized with the nanofibers. The nanofibres are then tested with paraoxon for its decontamination and observed the hydrolysis of simulant. The authors found that the reactivity and amount of adsorption of these catalysts are of higher capacity than the conventionally used activated charcoal. They have proposed a new design for protective wear based on these functionalized nanofibre membranes.

\subsection{Molecularly Imprinted Nano-fibers on Fabrics with Recognition Capability}

Molecular imprinting (MI) is an upcoming fabrication strategy that yields nano-structured assemblies possessing molecular recognition capabilities. Specifically, MI can produce materials with highly selective synthetic receptors for a variety of chemical and biochemical structures. Permanent cavities are formed in a material matrix or thin surface layer, which complement the functional and structural character of a template molecule. A key property of these molecularly imprinted materials (MIMs) is that they can recognize and bind targeted biomolecules in the presence of closely related chemical species. Creation of molecularly imprinted fibers (MIFs) with molecular recognition capability through fiber spinning and/or surface modification techniques and the resulting fibrous structures can be used in many fields. The 
three dimensional molecular imprinting approach has been effective for the construction of synthetic receptors for chemical warfare agent structures and metal ions [25, 26]. Molecular Imprinted Polymer (MIP) Networks [27] was developed based on graft polymerization technology to prepare MIPs on flat surfaces that allows characterizing the network's physical and chemical properties. The nature of atom transfer radical polymerization (ATRP) allows one to grow uniform MIP films and estimate with reasonable certainty the MIP film thicknesses that will coat the fibers. Template re-binding isotherms suggested that imprint sites occur throughout the film thickness, as opposed to being confined to the interface only. The authors have successfully transferred ATRP technique for preparation of MIPs on flat surfaces to the fabric fibers without affecting fabric morphology. Template rebinding isotherms on representative sets of MIP and non-imprinted polymer (NIP) fibers, as measured by batch adsorption studies showed significantly higher adsorption capacities for template molecules on imprinted fibers relative to nonimprinted fibers. There are many ways for future research in nanofibers in relation to defence clothing perspective. As well as serving protection and decontamination functions, nanofiber membranes also need to exhibit the durability, washability, resistance to intrusion of all liquids, and tear strength required of battledress fabrics.

\section{REFERENCES}

[1] W.B. Marzi, "Development of a new impermeable NBC protective suit for German civil defence" in the proceedings of the third international symposium on protection against chemical warfare agents, Stockholm, Sweden 11-16 June 1989, pp. 21-24, Swedish Defence Research Establishment, UMEA.

[2] M.G. Katz, "A new approach to heat stress relief in chemical protective clothing" in the proceedings of the third international symposium on protection against chemical warfare agents Stockholm, Sweden 11-16 June 1989, pp. 25-31, Swedish Defence Research Establishment, UMEA.

[3] G. Huzhang, H. Qitai and Z. Lei, "New carbon containing protective fabrics" in the proceedings of the third international symposium on protection against chemical warfare agents Stockholm, Sweden 11-16 June 1989, pp. 33-38, Swedish Defence Research Establishment, UMEA.

[4] G. Fang, H. Dingmao, L. Guojin, Z. Weixin, and L. Jiangge, "Adsorption properties of carbon containing flannel" in the proceedings of the third international symposium on protection against chemical warfare agents Stockholm, Sweden 11-16 June 1989, pp. 39-44, Swedish Defence Research Establishment, UMEA.

[5] G. Fang, "Chinese permeable chemical protective suits. Its test and evaluation" in the proceedings of the second international symposium on protection against chemical warfare agents, Stockholm, Sweden 15-19 June 1986, pp. 51-58, National Defence Research Establishment, Umea, Sweden.

[6] E.E. Alexandroff, "Saratoga carbon pellet technology in chemical warfare protective clothing" in the proceedings of the second international symposium on protection against chemical warfare agents, Stockholm, Sweden 15-19 June 1986, pp. 67-76, National Defence Research Establishment, Umea, Sweden.

[7] E.E. Alexandroff, "PBI Saratoga new and improved CWU/66p chemical protective clothing system for aircrew application" in the proceedings of the third international symposium on protection against chemical warfare agents, Stockholm, Sweden 11-16 June 1989, pp. 63-70, Swedish Defence Research Establishment, UMEA.

[8] E. Helper, "The new personal chemical protective suit of the U.S military services" in the proceedings supplement of the sixth international symposium on protection against chemical warfare agents", Stockholm, Sweden May 10-15, 1998, pp. 200, Swedish Defence Research Establishment, UMEA.

[9] S.G. Maroldo, "Carbonaceous resins-sorbents for chemical protection" in the proceedings of the third international symposium on protection against chemical warfare agents, Stockholm, Sweden 11-16 June 1989, pp. 71-78, Swedish Defence Research Establishment, UMEA.

[10] E. Helper, "The concept of using and under garment for the NBC protection" in the proceedings of the fourth international symposium on protection against chemical warfare agents, Stockholm, Sweden 812 June 1992, pp. 59, National Defence Research Establishment, Umea, Sweden.

[11] T. Stoll, "New generation of permeable NBC protection clothing for hot climate conditions" in the proceedings supplement of the sixth international symposium on protection against chemical warfare agents, Stockholm, Sweden May 10-15, 1998, pp. 202, Swedish Defence Research Establishment, UMEA.

[12] V. Obsel and V. Stein, "Czechosolavak textile adsorbents and possibilities of their utilization for noxious compounds trapping" in the proceedings of the fourth international symposium on protection against chemical warfare agents, Stockholm, Sweden 8-12 June 1992, pp. 63, National Defence Research Establishment, Umea, Sweden.

[13] P. Nousiainen, M. Nieminen, A. Vuori, and M. Ranta, "Visac activated carbon fibers in composites for chemically protective clothing" in the proceedings of the fourth international symposium on protection against chemical warfare agents, Stockholm, Sweden 8-12 June 1992, pp. 61, National Defence Research Establishment, Umea, Sweden.

[14] W. Vogel, "Cross laminated NBC protective films" in the proceedings of the third international symposium on protection against chemical warfare agents, Stockholm, Sweden 11-16 June 1989, pp. 55-60, Swedish Defence Research Establishment, UMEA.

[15] J.F. Stampfer and R.J. Beckman, "A screening test for selecting chemical protective clothing" in the proceedings of the second international symposium on protection against chemical warfare agents, Stockholm, Sweden 15-19 June 1986, pp. 41-49, National Defence Research Establishment, Umea, Sweden.

[16] B.J. Davey, "Degradation of human performance with use of chemical protective clothing" in the proceedings of the fourth international symposium on protection against chemical warfare agents, Stockholm, Sweden 8-12 June 1992, pp. 371-372, National Defence Research Establishment, Umea, Sweden.

[17] K.W. Ang, F.K. Lee and P.S. Quek, "New protective material test system: Evaluation of multiple challenge chemicals" in the proceedings supplement of the sixth international symposium on protection against chemical warfare agents, Stockholm, Sweden May 10-15, 1998, pp. 197, Swedish Defence Research Establishment, UMEA.

[18] R.J.V. Eenennaam, J. Kaaijk, M. Leeuw, H.F.G Oudmayer and G.J. Woudenberg, "Automated test system for NBC protective material" in the proceedings supplement of the sixth International symposium on protection against chemical warfare agents, Stockholm, Sweden May 10-15, 1998, pp. 198, Swedish Defence Research Establishment, UMEA.

[19] J. Medema, P.T. Van Raaij and P.M.M. Wittgen, "Protection afforded by NBCF suits (influence of wear and tear" in the proceedings of the second international symposium on protection against chemical warfare agents, Stockholm, Sweden 15-19 June 1986, pp. 77-89, National Defence Research Establishment, Umea, Sweden.

[20] G.R. Magin, "Decontamination of over garments" in the proceedings of the second international symposium on protection against chemical warfare agents, Stockholm, Sweden 15-19 June 1986, pp. 37-40, National Defence Research Establishment, Umea, Sweden.

[21] J. Medema and P.M.M. Wittgen, "Effect of laundering on antichemical protective clothing" in the proceedings of the fourth international symposium on protection against chemical warfare agents, Stockholm, Sweden 8-12 June 1992, pp. 65-73, National Defence Research Establishment, Umea, Sweden.

[22] S. Thandavamoorthy, N. Gopinath and S. S. Ramkumar, "Selfassembled honeycomb polyurethane nanofibers" J. Appl. Poly. Sci., vol. 101, pp. 3121-3124, September 2006.

[23] S. Ramakrishna, K. Fujihara, W.E. Teo, T. Yong, Z. Ma and R. Ramaseshan, "Electrospun nanofibers: Solving global issues" Mater. Today, vol. 9, pp. 40-50, March 2006.

[24] R. Ramaseshan, S. Sundarrajan, Y. Liu, R.S. Barhate, N. L. Lala and S. Ramakrishna, "Functionalized polymer nanofibre membranes for 
protection from chemical warfare stimulants" Nanotechnology, vol. 17, pp. 2947-2953, June 2006.

[25] M. Boopathi, M.V.S. Suryanarayana , A.K. Nigam, P. Pandey, K. Ganesan, B. Singh and K. Sekhar, "Plastic antibody for the recognition of chemical warfare agent sulphur mustard", Biosens. Bioelectron., vol. 21, pp. 2339-2344, June 2006.

[26] A. Baghel, M. Boopathi, B. Singh, P. Pandey, T.H. Mahato, P.K. Gutch, K. Sekhar, "Synthesis and characterization of metal ion imprinted nano-porous polymer for the selective recognition of copper, Biosens. Bioelectron., vol. 22, pp.3326-3334, June 2007.

[27] I. Luzinov, P. Brown and S. Husson, "Molecularly imprinted fibers with recognition capability" American National Textile Center Research Briefs: June 2007 [on line] available: www.ntcresearch.org/ pdf-rpts/Bref0607/Briefs07-TOC.pdf [Accessed September 4, 2008].

Received: September 05, 2008

(C) Boopathi et al.; Licensee Bentham Open.

This is an open access article licensed under the terms of the Creative Commons Attribution Non-Commercial License (http://creativecommons.org/licenses/bync/3.0/), which permits unrestricted, non-commercial use, distribution and reproduction in any medium, provided the work is properly cited. 